\title{
PENGEMBANGAN SOFTWARE AEROBIC CAPACITY DENGAN MENGGUNAKAN BLEEP TEST BERBASIS
} APLIKASI ANDROID

\author{
Moch Insan Gumelar, Hamidie Ronald Daniel Ray, Surdiniaty Ugelta \\ Program Studi Ilmu Keolahragaan \\ Departemen Pendidikan Kesehatan dan Rekreasi \\ Fakultas Pendidikan Olahraga dan Kesehatan \\ Universitas Pendidikan Indonesia, Jl. Dr. Setiabudhi No. 229 Bandung \\ Email: Insan.ocan13@gmail.com
}

\begin{abstract}
Abstrak
Penelitian ini bertujuan untuk membuat software instrument pengukur Bleep Test berbasis aplikasi android. Fungsi aplikasi Bleep Test ini yaitu untuk memandu jalannya tes yang memudahkan pengguna dalam pelaksanaan tes dengan pencatatan hasil yang otomatis. Aplikasi ini dibuat menggunakan aplikasi Intel XDK. Aplikasi ini menggunakan indikator berlari yang berbentuk animasi yang memudahkan pengguna, animasi ini juga akan bertambah cepat dengan bertambahnya level. Penelitian ini menggunakan pendekatan metode Research and Development (R\&D). Hasil uji coba dan uji validasi yang dilakukan dari tahap simulasi sampai uji coba dilapangan secara umum berfungsi dengan baik. Uji coba statistik menunjukan tiadak ada perbedaan yang signifikan dengan cara manual, sehingga aplikasi ini dapat digunakan. Output dari hasil penggunaan instrument ini dapat mengetahui berapa kekuatan aerobic maksimal atau Vo2Max yang selanjutnya hasil akan dianalisis dan dievaluasi oleh pelatih untuk meningkatkan performa atlet.
\end{abstract}

Kata kunci: Aplikasi Android, Bleep Test, VO2Max.

\section{PENDAHULUAN}

Salah satu faktor pendukung prestasi atlet yaitu $\mathrm{VO}_{2 \max }$ atau juga di sebut aerobic capacity. Aerobic capacity yaitu kemampuan jantung untuk memompakan darah yang kaya oksigen keseluruh bagian tubuh dan kemampuan menyesuaikan serta memulihkan dari aktivitas jasmani. Menurut Sharkey (2003) menyatakan bahwa "kapasitas aerobik adalah kapasitas untuk mengirup, menyalurkan dan menggunakan oksigen".Salah satu tes pengukuran VO2max yaitu bleeptes, menurut Iztok Kavcic1 dkk. (2012) menyatakan bahwa "The multi-stage 20-m shuttle run test (MSRT) is one of the most popular field test using equations based on test results or the final speed for an indirect estimation of maximal oxygen uptake (VO2max)". dari pernyataan diatas dapat disimpulkan bahwa multi-stage 20$m$ shuttle run test atau disebut juga bleep tes merupakan salah satu tes lapangan yang populer digunakan untuk mencari nilai perkiraan VO2max. Data nilai VO2max tersebut digunakan sebagai evaluasi bagi atlet, baik evaluasi dalam latihan maupun sebagai parameter ketercapaian latihan.

Menurut Zacky Tuah (2014) menyatakan bahwa dalam pelaksanaannya atlet harus berlari dari titik A ke titik B dengan mengikuti irama dari suara bell(beep),kecepatan akan semakin bertambah setiap levelnya dan atlet akan semakin cepat berlari ketika levelnya bertambah, atlet juga wajib melewati garis yang sudah di berikan oleh petugas, karena garis adalah batas jarak yang harus di tempuh atlet 
dan apabila atlet tidak sampai melewati garis ketika bell berbunyi selama 2xberturut-turut maka atlet dinyatakan gugur atau tidak bisa melanjutkan tes tersebut. Dalam pelaksanaannya juga di butuhkan satu orang pelari dan satu orang yang mencatat data level yang berlari,

Kekurangan dari cara manual yaitu terlalu banyak memerlukan orang untuk mencatat hasil dan setelah ada hasil tes harus kembali di olah agar di ketahui berapa VO2maxnya, tidak adanya irama setiap level yang membuat atlet tidak tau harus berlari dengan kecepatan seperti apa setiap levelnya, tidak di ketahui berapa jarak yang di tempuh dan waktu selama melakukan tes. Supaya mendapatkan hasil VO2max yang akurat dibutuhkan instrument yang memadai yaitu dengan bantuan software agar pelaksanaannya dilaksanakan secara efektif dan efesien. Software merupakan program yang menerapkan sebuah fungsi tertentu di dalam komputer yang langsung dapat digunakan oleh penggunanya. Fungsi software dalam bleep test dalam hal ini yaitu sebagai pemandu jalannya bleep test baik secara individu ataupun secara tim dengan hanya menginput data tester kemudian mengklik tombol start dan stop di dalam software maka bleep test sudah dapat berjalan dengan penghitungan hasil yang otomatis juga akurat, dan permasalahan seperti yang di atas bisa diminimalisir.

Berdasarkan pengamatan penulis setelah mencari sumber di internet dari banyaknya website yang menulis tentang bleep test diperkuat dengan pernyataan pakar olahraga di salah satu perguruan tinggi keolahragaan di Indonesia, bahwa belum adanya software bleep tes berbasis aplikasi android yang di realease dari Indonesia. Maka dari itu penulis ingin membuat produk software bleep tes yang berbasis android yang lebih lengkap dari sebelumnya.

\section{METODE}

Dalam penelitian ini metode yang digunakan adalah metode Research and Development (R\&D). Menurut Sugiyono (2012, hlm. 297) menyatakan bahwa, "Metode penelitian Research and Development (R\&D) adalah metode penelitian yang digunakan untuk menghasilkan produk tertentu dan menguji keefektifan produk tersebut". Alasan penggunaan metode ini dikarenakan hasil akhir penelitian ini akan menghasilkan produk pengembangan software aerobic capacity dengan menggunakan bleep test berbasis aplikasi android.

Peneliti melibatkan tiga pengujian untuk menilai produk penelitian, yaitu : (1) Penguji ahli olahraga; (2) Penguji bidang IT; dan (3) Pengguna. Penguji ahli dalam bidang olahraga adalah seorang ahli dibidang olahraga berfungsi menilai apakah alat ini layak di uji cobakan atau direvisi kembali. Sehingga alat ini sesuai dengan kebutuhan bidang olahraga. Sedangkan penguji bidang IT (Ilmu Teknologi) berfungsi untuk menilai software ini. Dan untuk pengguna, peneliti menggunakan angket untuk mengetahui pendapat apakah software ini nyaman, efektif, dan akurat untuk di gunakan pada saat pengetesan.

Sebanyak 20 orang mahasiswa keolahragaan berpartisipasi dalam ujicoba aplikasi bleep test ini. Pelaksanaan tesnya semua sampel melalukan dalam satu periode, pertama sampel melakukan pemanasan, setelah itu sampel baris untuk mengisi data diri dan di masukan ke software setelah itu sampel berdiri di garis A menghadap ke garis B dan siap untuk melakukan tes. Setelah sampel siap software android di klik mulai oleh operator, setelah mulai pengetesan hanya tinggal menunggu sampel yang kelelahan dan mengklik selesai di kolom sampel yang sudah kelelahan, setelah semua sampel melakukan tes akan keluar hasil VO2max. Setelah pengetesan VO2max selesai selanjutnya dilakukan pengisian angket, sampel diminta mengisi angket yang membandingkan antara bleep test cara manual atau bleep test menggunakan software aplikasi android.

\section{HASIL DAN PEMBAHASAN}

Hasil Software bleep test ini pun di program untuk memberikan laporan hasil tes secara otomatis jika tombol fungsi selesai sudah ditekan, tanpa harus mengetik ulang dan menkonversikan hasil bleep test dengan tabel VO2max dari para ahli. Keuntungan menggunakan software ini adalah user 
(pengguna software) hanya perlu input data tester, kemudian tombol mulai di klik maka bleep test dapat langsung berjalan, jika bleep test sudah dianggap selesai maka user hanya perlu klik tombol selesai untuk memberhentikan secara individu dan tombol selesai untuk memberhentikan proses, setelah itu hasil akan keluar secara otomatis. Inovasi lainnya yang ada dalam aplikasi ini adalah jumlah pengguna yang dapat memuat lebih dari 1000 orang dalam satu tes, kemudian dalam aplikasi ini indikator kecepatan berlari berupa animasi yang memudahkan pengguna membaca irama beep. Selain itu pencatatan yang otomatis akan mengurangi kesalahan dalam hasil tes.

Berdasarkan hasil pengambilan data bleep test cara manual dan bleep test software android tidak terdapat perbedaan yang signifikan antara bleep test cara manual dan bleep test software android. Hal ini sejalan dengan penelitian sebelum nya oleh Agni, F., 2014 yang mnunjukkan hasil tidak terdapat perbedaan yang signifikan atara tes dengan cara manual dengan mengguakan software komputer. Dalam rangka memperkuat hasil penelitian kali ini maka terdapat perbedaan dengan penelitian sebelumnyayaitu dengan menambahkan instrumen angket yang bertujuan membuat aplikasi ini menjadi lebih baik dibandingkan dengan tes cara manual sesuai dengan hasil angket yang di dapat.

Berdasarkan hasil angket yang di dapat di bagi menjadi beberapa kategori yang pertama yaitu tingkat kepuasan, efektif, akurat, dan audio visual. Hasil dari tingkat kepuasan dari teste sangat tinggi karena software ini mudah untuk di gunakan dan tidak membutuhkan banyak SDM (Sumber Daya Manusia). Hasil dari tingkat efektif sangat tinggi juga karena software bisa digunakan lebih dari ratusan orang untuk sekali periode tes sehingga menjadikan software ini lebih efektif dibandingkan cara manual. Hasil dari tingkat akurat juga tinggi dikarenakan hasil yang di keluarkan dari output ini mengacu kepada aturan dan norma bleep test yang sudah ada.
Hasil dari tingkat audio visual juga baik karena suara yang di keluarkan terdengar oleh atlet. Dengan hasil ini menyatakan bahwa software android yang di buat oleh peneliti sangat mudah, nyaman, dan efektif (bisa di lakukan oleh banyak orang) dan ini sejalan dengan pendapat Menurut Iztok Kavcic1 dkk. (2012:18) bahwa tesini merupakan tes yang dianggap valid, aman, murah dan reliabel untuk dilakukan oleh sekelompok atau banyak orang. Berdasarkan pakar ahli Olahraga Iman Imanudin, S.Pd., M.Pd. pakar kondisi fisik di Universitas Pendidikan Indonesia mengungkapkan bahwa aplikasi ini sudah sangat baik karena aplikasi ini bisa digunakan ratusan orang untuk sekali periode pengetesan dan aplikasi ini sangat membantu pengguna pada saat pengetesan karena tidak perlu memerlukan SDM (Sumber Daya Manusia). Sedangkan hasil dari pakar IT (Ilmu Teknologi)Faisal Mahasiswa Ilmu Komputer Universitas Pendidikan Indonesia, mengungkapkan bahwa semua tombol dalam aplikasi ini berfungsi sesuai fungsinya masingmasing. Secara umum pakar ahli olahraga dan pakar ahli IT (Ilmu Teknologi) ini bertujuan untuk mengetahui apakah perintah perintah yang ada dalam software berfungsi atau tidak, kemudian untuk mengetahui apakah software telah diprogram sesuai dengan aturan Bleep testatau tidak, seperti pengaturan program level, balikan dan hasil perkiraan VO2max.

\section{KESIMPULAN}

Hasil dari penelitian ini membandingkan instrumen mana yang lebih baik antara bleep test dengan menggunakan cara manual dan cara software berbasis aplikasi android, dan setelah di teliti oleh penulis bleep test dengan software berbasis aplikasi android lebih nyaman, efektif, efesien dibandingkan dengan cara manual dikuatkan dengan hasil angket yang di sebarkan oleh penulis. 


\section{DAFTAR PUSTAKA}

Adhikarmika Uliyandari (2009). Pengaruh Latihan Fisik Terprogram Terhadap Perubahan Nilai Konsumsi, Oksigen Maksimal (vo2max) Pada Siswi Sekolah Bola Voli Tugu Muda Semarang Usia 11-13 Tahun. Karya Tulis Ilmiah Universitas Diponegoro.

Amstrong, N. (2006). Aerobic Fitness of children and adolescent, Jornal de Pediatria $2006 ; 82 ; 406$.

Dito Endero Nakresna (2014).Intel XDK.

Fox SI. Muscle. (2003). Mechanism of Contraction and Neural Control In : Fox SI Human Physiology, 8nd ed. Kota : McGraw-hill;2003.p, 343.

Giriwijoyo, Santosadan Sidik, Dikdik Z. (2012).Ilmu Faal Olahraga (Fisiologi Olahraga). Fungsi Tubuh Manusia Pada Olahraga untuk Kesehatan dan Prestasi. Bandung : Remaja Rosdakarya.

Iztok Kavcic dkk. (2012).Comparative study of measured and predicted vo2maxduring a multi-stage Fitness test with junior soccer players. Comparative study of measured and predicted. Kinesiology (2012).

Imanudin, Iman. (2008). Ilmu Kepelatihan Olahraga. Bandung : Universitas Pendidikan Indonesia.

James A O’Brien (2008).Buku Rekayasa Perangkat Lunak

Matjan, Bastinus. (2010). Modul ilmu kesehatan Olahraga. Bandung : FPOK UPI Bandung

Mackenzie, Brian. (2005). 101performance evaluation test.

Murtiwiyati dan Lauren, Glenn. (2013). Rancang Bangun Aplikasi Pembelajaran Budaya Indonesia Untuk Anak Sekolah Dasar Berbasis Android. Jurnal Ilmiah KOMPUTASI. Vol 12: 2.

Nurhasan. (2007). Tes dan Pengukuran Keolahragaan. Bandung: FPOK UPI

Sidik, Dikdik Z. (2010) Pembinaan Kondisi Fisik. Bandung : Jurusan pendidikan kepelatihan FPOK UPI.

Sugiyono (2012) Metode Penelitian Kuantitatif Kualitatif dan $R \& D$.

Suwandhana Yunizar. 2015. Hubungan antara kecerdasan intelektual dan kecerdasan emosional dengan prestasi akademik.(Skripsi). Bandung. Universitas Pendidikan Indonesia.

Yatini, Indra. (2014). Aplikasi Pengolahan Citra Berbasis Web Menggunakan Javascript dan JQuery. Jurnak Teknik. Vol 3: 3. 